\title{
Determination of the Error in Transferring of Length Unit's Size when Measuring the Nanoparticles' Diameter Using an Analyzer of Particles' Differential Electrical Mobility
}

\author{
V.L. Solomakho' ${ }^{1}$ A.A. Bagdun ${ }^{2}$ \\ ${ }^{1}$ Belarusian National Technical University, \\ Nezavisimosti Ave., 65, Minsk 220013, Belarus \\ ${ }^{2}$ Belarusian State Institute of Metrology, \\ Starovilensky trakt, 93, Minsk 220053, Belarus
}

Received 09.07.2021

Accepted for publication 01.09.2021

\begin{abstract}
The quality of nanomaterials and nanotechnologies is largely determined by the stability of the applied technologies, which, to a large extent, depend on the constancy of particle sizes. In this regard, metrological problems arise that are associated both with measuring the dimensions of the microstructure of aerosols, suspensions and powders, and with ensuring the uniformity of measurements when transferring a unit of a physical quantity from a standard to working measuring instruments. The purpose of this work was to determine and calculate the error in transferring the size of a unit of length when measuring the diameter of nanoparticles.

An analyzer of differential electric mobility of particles was determined as a reference measuring instrument for which the calculation was made. It allows the separation of aerosol particles based on the dependence of their electrical mobility on the particle size. In combination with a condensation particle counter, it allows you to scan an aerosol and build a particle size distribution function. This measurement method is the most accurate in the field of measuring the diameters of particles in aerosols, therefore, the error in the transmission of particle size must be set as for a standard.

The paper describes the physical principles of measurement by this method and presents an equation for determining the diameter of nanoparticles. Based on this equation, the sources of non-excluded systematic error were identified. Also, an experimental method was used to determine the random component of the measurement error of nanoparticles and to calculate the error in transferring the size of a unit of length when measuring the diameter of nanoparticles.

The obtained results will be used for metrological support of standard samples of particle size, ensuring traceability of measurements of aerosol particle counters and for aerosol research.
\end{abstract}

Keywords: nanoparticles, electrical mobility, traceability of measurements, diameter of nanoparticles.

DOI: $10.21122 / 2220-9506-2021-12-3-194-201$

\begin{tabular}{|c|c|}
\hline $\begin{array}{l}\text { Адрес для переписки: } \\
\text { Багдюн А.А. } \\
\text { Белорусский государственный институт метрологии, } \\
\text { Старовиленский тракт, 93, г. Минск 220053, Беларусь } \\
\text { e-таil: bagdun.ne@gmail.com }\end{array}$ & $\begin{array}{l}\text { Address for correspondence: } \\
\text { Bagdun A.A. } \\
\text { Belarusian State Institute of Metrology, } \\
\text { Starovilensky trakt, 93, Minsk 220053, Belarus } \\
\text { e-mail: bagdun.ne@gmail.com }\end{array}$ \\
\hline $\begin{array}{l}\text { Для цитирования: } \\
\text { V.L. Solomakho, A.A. Bagdun. } \\
\text { Determination of the Error in Transferring of Length Unit’s Size } \\
\text { when Measuring the Nanoparticles' Diameter Using an Analyzer } \\
\text { of Particles’ Differential Electrical Mobility. } \\
\text { Приборы и методы измерений. } \\
\text { 2021. - Т. 12, № 3.- C. 194-201. } \\
\text { DOI: } 10.21122 / 2220-9506-2021-12-3-194-201 \\
\end{array}$ & $\begin{array}{l}\text { For citation: } \\
\text { V.L. Solomakho, A.A. Bagdun. } \\
\text { Determination of the Error in Transferring of Length Unit's Size } \\
\text { when Measuring the Nanoparticles' Diameter Using an Analyzer } \\
\text { of Particles' Differential Electrical Mobility. } \\
\text { Devices and Methods of Measurements. } \\
\text { 2021, vol. } 12 \text {, no. 3, pp. 194-201. } \\
\text { DOI: } 10.21122 / 2220-9506-2021-12-3-194-201\end{array}$ \\
\hline
\end{tabular}




\title{
Определение погрешности передачи размера единицы
}

\section{длины при измерении диаметра наночастиц с помощью анализатора дифференциальной электрической подвижности частищ}

\author{
В.Л. Соломахо ${ }^{1}$, А.А. Багдюн ${ }^{2}$ \\ ${ }^{1}$ Белорусский национальный технический университет, \\ nр-т Независимости, 65, г. Минск 220013, Беларусь \\ ${ }^{2}$ Белорусский государственный институт метрологии \\ Старовиленский тракт, 93, г. Минск 220053, Беларусь
}

Поступила 09.07.2021

Принята к печати 01.09.2021

Качество наноматериалов и нанотехнологий во многом определяется стабильностью применяемых технологий, которые в значительной степени зависят от постоянства размеров частиц. В связи с этим возникают метрологические задачи, связанные как собственно с измерением размеров микроструктуры аэрозолей, суспензий и порошков, так и с обеспечением единства измерений при передаче единицы физической величины от эталонного к рабочим средствам измерений. Целью данной работы являлось определение и расчёт погрешности передачи размера единицы длины при измерении диаметра наночастиц.

В качестве эталонного средства измерения, для которого производился расчёт, был определён анализатор дифференциальной электрической подвижности частиц. Он позволяет разделять частицы аэрозоля на основе зависимости их электрической подвижности от размера частиц. В комбинации с конденсационным счётчиком частиц позволяет сканировать аэрозоль и строить функцию распределения частиц по размерам. Данный метод измерения является самым точным в области измерения диаметров частиц в аэрозолях, поэтому погрешность передачи размера частиц необходимо установить как для эталона.

В работе описаны физические принципы измерения данным методом и представлено уравнение для определения диаметра наночастиц. На основании данного уравнения были определены источники неисключённой систематической погрешности. Также экспериментальным методом определена случайная составляющая погрешности измерения наночастиц и рассчитана погрешность передачи размера единицы длины при измерении диаметра наночастиц.

Полученные результаты будут использованы для метрологического обеспечения стандартных образцов размера частиц, обеспечения прослеживаемости измерений счётчиков аэрозольных частиц и для исследований аэрозолей.

Ключевые слова: наночастицы, электрическая подвижность, прослеживаемость измерений, диаметр наночастиц.

DOI: $10.21122 / 2220-9506-2021-12-3-194-201$

\begin{tabular}{ll}
\hline Адрес для переписки: & $\begin{array}{l}\text { Address for correspondence: } \\
\text { Багдюн А.А. }\end{array}$ \\
$\begin{array}{l}\text { Белорусский государственный институт метрологии, } \\
\text { Старовиленский тракт, 93, г. Минск 220053, Беларусь }\end{array}$ & $\begin{array}{l}\text { Starovilensky trakt, 93, Minsk 220053, Belarus } \\
\text { e-mail: bagdun.ne@gmail.com }\end{array}$ \\
e-таil: bagduп.пе@gmail.com & For citation: \\
\hline Для цитирования: & V.L. Solomakho, A.A. Bagdun. \\
V.L. Soloтаkho, A.A. Bagdun. & Determination of the Error in Transferring of Length Unit’s Size \\
Determination of the Error in Transferring of Length Unit’s Size & when Measuring the Nanoparticles’ Diameter Using an Analyzer \\
when Measuring the Nanoparticles’ Diameter Using an Analyzer & of Particles’ Differential Electrical Mobility. \\
of Particles’ Differential Electrical Mobility. & Devices and Methods of Measurements. \\
Приборы и методы измерений. & 2021, vol. 12, no. 3, pp. 194-201. \\
2021. - Т. 12, № 3.- С. 194-201. & DOI: 10.21122/2220-9506-2021-12-3-194-201 \\
DОI: 10.21122/2220-9506-2021-12-3-194-201 &
\end{tabular}




\section{Introduction}

Nanoparticles and nanotechnology are one of the most promising areas of scientific development at the present stage, creating preconditions for solving various applied technological problems. All over the world, a huge number of "nanoproducts" are being developed, based on the use of nanoparticles, which make it possible to obtain new quality products and technologies [1].

Nanostructured (nanophase, nanocrystalline, subpremolecular) materials traditionally include materials with microstructure sizes from 1 to $100 \mu \mathrm{m}$. This definition of dimensional boundaries is not accidental. The lower limit is associated with the loss of some symmetry elements in crystals of nanocrystalline materials as their size decreases. The value of the upper limit is due to the fact that noticeable "useful", from a technical point of view, changes in the physicomechanical, chemical, electrical, optical, tribological and other properties of materials sharply decrease with a further increase in the particle size $[2,3]$.

Currently, the priority interest in the development of nanomaterials and nanotechnology is due to $[4,5]$ :

- using the unique properties of materials in a nanostructured state;

- development of technologies for obtaining nanoclusters and nanostructures;

- the need to develop and implement new materials with qualitatively new properties;

- the desire for miniaturization of products;

- the practical implementation of modern methods and means of control, including nanoobjects and nanomaterials, etc.

The quality of products is determined by the stability of technologies, which, in relation to nanotechnology, largely depend on the constancy of particle sizes. Among the characteristics defined by the Organization for Economic Cooperation and Development, the determination of particle size is determined by the most important element in the study of the properties of nanoparticles.

Therefore, the harmonization of methods for measuring the size of nanoparticles is extremely demanded, firstly, to ensure the continuous development of nanotechnology and support trade in nanoproducts, and secondly, to assess the potential danger of their impact on the environment, health and safety of human life [6]. Under these conditions, it is very important to ensure the metrological traceability of measurements of nanoparticles, including the creation of the necessary reference means of changes.

There are various methods for measuring linear quantities in this size range. In particular, the stan-

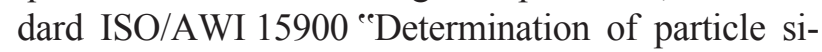
ze distribution. Differential analysis of the electrical mobility of particles in aerosols" provides that the measurement of particle sizes in the analysis of the disperse composition of gaseous media is carried out using a differential particle mobility analyzer (DMA).

\section{Physical principles of measuring particle diameters by electrical mobility}

This method is based on the physical principle of differential electrical mobility analysis, which separates aerosol particles based on the dependence of their electrical mobility on particle size. The electric mobility of a particle $Z$ is equal to the velocity $U$ of a charged particle divided by the strength of the electric fields $E$ :

$Z=\frac{U}{E}$.

Electric mobility is calculated from the balance of electric forces arising from the charge on the particle and the resistance force determined by Stokes' law:

$n e E=\frac{3 \pi \mu U D_{P}}{C\left(D_{P}\right)}$,

where $n$ is the number of charges; $e$ is the electron charge; $\mu$ is the viscosity of the gas; $D_{p}$ is the particle diameter; $C\left(D_{p}\right)$ is Cunningham slip correction.

The charge distribution on particles depending on their size is based on a theoretical model arising from the theory of diffusion for particles of the submicron range, based on the Fuchs approximation.

Figure 1 shows curves calculated according to Fuchs theory, where $f_{N}(d)$ is the particle charge; $d$ is the particle size.

The size distribution of particles carrying zero, one or two elementary charges at an equilibrium charge is expressed by the equation derived from the Fuchs model:

$f_{N}(d)=10^{\sum a_{i}(N) \cdot(\log d)^{i}}$,

where the particle size $d$ is expressed in nm, the values of the coefficient $a_{i}(N)$ were determined using least squares analysis and are indicated in Table 1 [7]. 


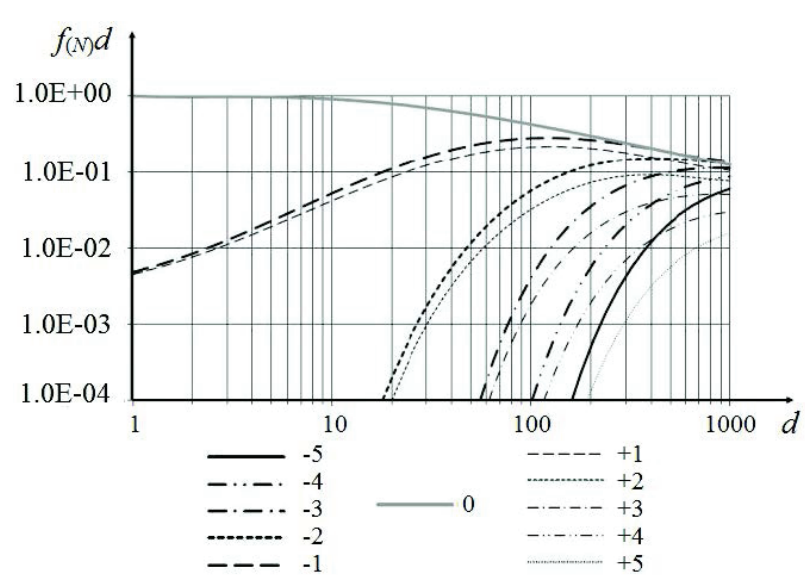

Figure 1-Charge distribution function for particles in the size range between 1 and $1000 \mathrm{~nm}$, where the numbers denoting the curve are the number of elementary charges carried by the particle

Table 1

Coefficients $a_{i}(N)$ for formula (3) for a bipolar charge conditioner with a $9.5 \mathrm{kV} \mathrm{X}$-ray ion source

\begin{tabular}{cccccc}
\hline \multirow{2}{*}{$i$} & \multicolumn{5}{c}{$a_{i}(N)$} \\
\cline { 2 - 6 } & $N=-2$ & $N=-1$ & $N=0$ & $N=1$ & $N=2$ \\
\hline 0 & -30.616 & -2.335 & 0.002 & -2.359 & -27.253 \\
1 & 46.339 & 0.436 & -0.114 & 0.452 & 38.480 \\
2 & -31.182 & 1.087 & 0.334 & 0.998 & -24.271 \\
3 & 11.391 & -0.557 & -0.357 & -0.482 & 8.442 \\
4 & -2.220 & 0.050 & 0.108 & 0.026 & -1.606 \\
5 & 0.179 & 0.006 & -0.011 & 0.008 & 0.129 \\
\hline
\end{tabular}

Equation (3) is valid for a range of particle sizes:

$1 \mathrm{~nm} \leq d \leq 1000 \mathrm{~nm}$ for $N=(-1 ; 0 ; 1)$;

$20 \mathrm{~nm} \leq d \leq 1000 \mathrm{~nm}$ for $N=(-2 ; 2)$.

The size distribution of particles carrying three or more elementary charges is calculated by the formula:

$f_{N}(d)=\frac{e}{\sqrt{4 \pi \varepsilon_{0} d k T}} \exp \left\{\frac{-\left[N-(2 \pi d k T) / e^{2}\right]}{2\left[(2 \pi d k T) / e^{2}\right]} \ln \left(Z_{+i} / Z_{-i}\right\}\right.$,

where $\varepsilon_{0}$ is the dielectric constant of the gas (for air $\left.\varepsilon_{0}=1.602 \cdot 10^{-12} \mathrm{~F} / \mathrm{m}\right) ; k$ is the Boltzmann constant; $T$ is the gas temperature; $Z_{+i} / Z_{-i}$ is ratio of ion mobility.

Coefficient $C\left(D_{p}\right)$ tends to unity for a particle whose diameter is greater than its mean free path in gas, and increases with decreasing particle diameter. In the case of singly charged particles, $n=1$. Then the following expression for the electric mobility is derived from equations (1) and (2):

$Z=\frac{e C\left(D_{P}\right)}{3 \pi \mu D_{P}}$.

\section{Electrostatic classifier device}

The electrostatic classifier, which includes the DMA, is structured as follows (Figure 2).

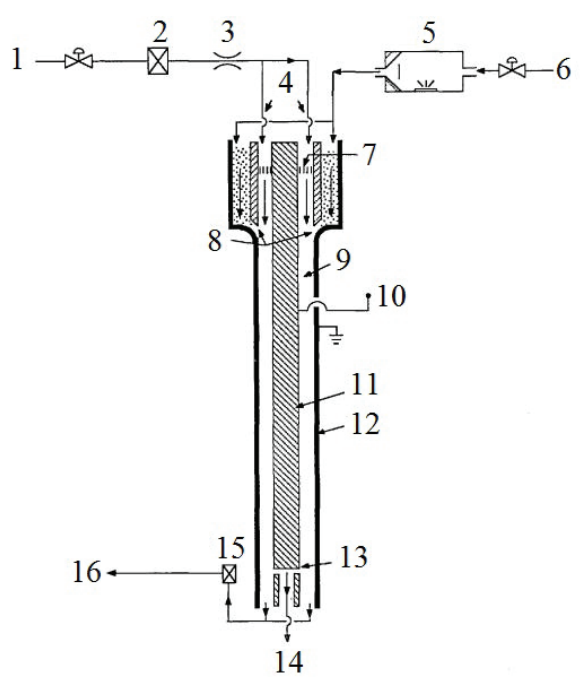

Figure 2-Schematic representation of the cylindrical classifier: 1 - blowing air supply channel $\left(q_{s h}\right) ; 2$ - high efficiency particulate air filter; 3 - flow meter; 4 - channel of clean air; 5-aerosol neutralizer; 6-channel for supplying polydisperse aerosol; 7 -flow straightener; 8 - aerosol inlet; 9 - classification area; 10 - high voltage source; 11 -central rod $\left(r_{1}\right)$, which is supplied with high voltage $(\mathrm{V}) ; 12$ - outer cylinder $\left(r_{2}\right) ; 13$ - exit slit of monodisperse aerosol; 14 - channel for the exit of monodisperse aerosol; 15 - filter; 16 - channel for the exit of polydisperse aerosol

This device allows you to separate aerosol particles based on their electrical mobility and, accordingly, create a stream of monodisperse particles at the outlet.

The classifier contains a bipolar charger (aerosol neutralizer). Here, the particles collide with bipolar ions, which leads to an equilibrium charge distribution that depends on the particle size. For example, according to diffusion theory for submicron particles, $100 \mathrm{~nm}$ particles will definitely exit the bipolar charger with $42.6 \%$ uncharged particles; $24.1 \%$ with +1 charge; $24.1 \%$ with a charge of -1 ; and the remaining particles are multiply charged.

After passing through the bipolar charger, the aerosol enters the DMA, also located inside the classifier. The DMA is a long cylindrical chamber with a radius of $1.958 \mathrm{~cm}$. Inside the chamber there is a rod with a radius of $0.937 \mathrm{~cm}$, concentric with the walls of the chamber, so that an annular space is formed between the rod and the walls of the chamber. 
The aerosol stream enters the upper part of the chamber and is combined with a stream of clean blowing air. The combined flow flows into the gap between the coaxially located central rod and the outer cylinder. The voltage on the rod can be adjusted from 0 to $10.000 \mathrm{~V}$. The outer cylindrical chamber is supported by ground potential, which allows the electric field to spread evenly in the annular space to the bottom of the chamber. Along the way, charged particles move to the central rod due to the voltage potential difference.

By changing the voltage on the central rod, thereby scanning the electric field strength, and by measuring the numerical concentration of the aerosol coming out of the slit, the distribution of the electric mobility of the particles is determined.

The small radial clearance and high uniformity of the electric field create the necessary conditions for high-resolution electrical mobility measurements.

A small gap in the rod allows you to classify particles with electrical mobility $Z$, calculated using the following formula:

$$
Z=\frac{q_{s h}}{2 \pi V L} \ln \left(\frac{r_{2}}{r_{1}}\right)
$$

where $q_{s h}$ is the blowing air flow rate in the shell; $V$ is the voltage on the rod; $L$ is the length from the aerosol inlet to the slot; $r_{1}$ and $r_{2}$ are the inner and outer radii of the annular space, respectively.

By adjusting the voltage, particles with a narrow range of mobility are selected. The yield of nearly monosized particles is achieved by selecting particles based on their mobility. A stream of monosized particles passes through the rod hole and exits the classifier, then to the condensation particle counter, where the number of particles is counted. The rest of the stream leaves the classifier through an excess stream outlet and enters the recirculation system. The recirculation system pumps casing air through the classifier, draws out excess air and then conditions it before returning it as a casing air stream.

From equations (4) and (5), the particle diameter is equal to:

$$
D_{P}=\frac{e C\left(D_{P}\right) 2 V L}{q_{s h} 3 \mu \ln \left(\frac{r_{2}}{r_{1}}\right)} .
$$

\section{Determination of sources of non-excluded systematic error}

Based on equation (6), a model was built for calculating the main sources of non-excluded systematic errors when measuring the diameter of particles in air using DMA:

$$
\theta_{L}=f\left(\delta e, \delta \mu, \delta C\left(D_{P}\right), \delta\left(L, \eta_{1}, r_{2}\right), \delta V, \delta q_{s h}\right),
$$

where $\delta_{e}$ is the error due to the determination of the magnitude of the electron charge; $\delta \mu$ is the error due to the determination of the value of the gas viscosity; $\delta C\left(D_{p}\right)$ error due to the determination of the Cunningham correction factor; $\delta\left(L, r_{1}, r_{2}\right)$ the error caused by the measurement of the geometric parameters of the DMA; $\delta V$ is the error due to the voltage measurement on the central rod of the DMA; $\delta q_{s h}$ is the error due to the measurement of the blowing air flow rate in the DMA casing.

\section{Quantification of the main sources of non- excluded systematic measurement error}

The error due to the determination of the magnitude of the electron charge

The magnitude of the electron charge and its standard deviation $(1 \sigma)$ are equal to $(1.6021892 \pm 0.0000046) \cdot 10^{-19} \mathrm{C}$. The relative error is about $3 \cdot 10^{-4} \%$ and is negligible when estimating the boundaries of the non-excluded systematic error.

\section{Error due to the determination of the gas viscosity}

R.T. Birge established a weighted average of the viscosity of dry air at $23.00{ }^{\circ} \mathrm{C}$ equal to $\mu_{0}=(1.83245 \pm 0.00069) \cdot 10^{-5} \mathrm{~kg} \mathrm{~m}^{-1} \mathrm{~s}^{-1}$, corrected for temperature using the Sutherland equation. After determining the reference viscosity at $23.00{ }^{\circ} \mathrm{C}$, the viscosity for other temperatures can be obtained using the Sutherland formula:

$$
\mu=\mu_{0}\left(\frac{T}{T_{0}}\right)^{1.5}\left(\frac{T_{0}+110.4 K}{T+110.4 K}\right),
$$

where $T_{0}$ is the absolute reference temperature $(296.15 \mathrm{~K}) ; T$ is the absolute temperature.

The viscosity of dry air at $23.00{ }^{\circ} \mathrm{C}$ has a relative error of $0.038 \%$. The air flowing through the DMA has an estimated relative humidity of $7 \%$. The reduction in viscosity due to the addition of water is estimated at $0.08 \%$ based on the viscosity of the water and its air volume fraction. This value of $0.08 \%$ is taken as the relative error in determining the viscosity of air due to the presence of water vapor. Calculating the relative error in determining 
the viscosity of a gas as a root of the sum of squares, we get a value of $0.089 \%$.

Error due to the determination of the Cunningham correction factor (slip correction)

The slip correction extends the calculation based on the Stokes law of the retarding force acting on a spherical particle moving with a low Reynolds number in a gas medium to particles of the order of a nanometer.

The Cunningham slip correction factor, which describes the behavior of a gas in an inhomogeneous medium when small particles move, is determined by the expression:

$$
C\left(D_{P}\right)=1+K_{n}\left[A_{1}+A_{2} \exp \left(-A_{3} / K_{n}\right)\right]=1+K_{n} A,
$$

where $K_{n}$ is the Knudsen number, namely, the doubled free path of particles in air divided by the particle diameter $\left(K_{n}=2 \lambda / D_{p}\right) ; A_{1}, A_{2}, A_{3}$ dimensionless constants; $A$ is slip correction parameter. The error due to the determination of the Cunningham correction factor is taken to be $0.1 \%$, which corresponds to the type $A$ uncertainty from the study [8].
Error due to geometric parameters measurement of the DMA

The error caused by the measurement of the geometric parameters of the DMA includes the errors in measuring the length from the aerosol inlet to the slit (analyzer length $L$ ), the inner and outer radii of the annular space $\left(r_{1}, r_{2}\right)$. The listed errors are $0.5 \%, 0.1 \%$ and $0.6 \%$, respectively [9]. Calculating the error due to the measurement of the geometric parameters of the DMA as the root of the sum of squares, we get a value of $0.7 \%$.

Error due to voltage measurement on the center rod of the DMA

The error due to voltage measurement on the central rod of the DMA is indicated in the calibration certificate for the electrostatic classifier and is $0.3 \%$.

The error due to the measurement of the blowing air flow rate in the sheath of the DMA

The error due to the measurement of the blowing air flow rate in the DMA casing is specified in the calibration certificate for the electrostatic classifier and is $2.0 \%$.

The main sources of non-excluded systematic errors and their values are shown in Table 2.

Table 2

\section{Sources of non-excluded systematic errors}

\begin{tabular}{|c|c|c|}
\hline Error name & Source of non-excluded systematic errors & Error value $\theta_{i}, \%$ \\
\hline$\delta e$ & Error due to the determination of the magnitude of the electron charge $e$ & 0.0003 \\
\hline$\delta \mu$ & Error due to the determination of the value of the viscosity of the gas $\mu$ & 0.089 \\
\hline$\delta C\left(D_{p}\right)$ & Error due to the determination of the Cunningham correction factor $C\left(D_{p}\right)$ & 0.1 \\
\hline$\delta\left(L, r_{1}, r_{2}\right)$ & $\begin{array}{l}\text { Error due to the measurement of the geometric parameters of the DMA } \\
\qquad\left(L, r_{1}, r_{2}\right)\end{array}$ & 0.79 \\
\hline$\delta V$ & Error due to measuring voltage $V$ at the center rod of the DMA & 0.3 \\
\hline$\delta q_{s h}$ & Error due to the measurement of the air flow velocity $q_{s h}$ in the DMA shell & 2.0 \\
\hline \multicolumn{3}{|c|}{ Non-excluded systematic error $\theta_{L}$} \\
\hline$\theta_{L}=K \sqrt{ } \sum$ & & $1.1 \times 2.18$ \\
\hline \multicolumn{3}{|c|}{ Note: a confidence interval $P=0.95 ; K=1.1$} \\
\hline Non-exclude & stematic error $\theta_{L}$ & 2.4 \\
\hline
\end{tabular}




\section{Determination of the standard deviation of the random component of the analyzer error when measuring the size of nanoparticles in air}

The standard deviation of the random component of the analyzer error in measuring the particle size in air was determined from standard samples of PSL particle size with a nominal value of $100 \mathrm{~nm}$. This particle size is typical and is used to represent the accuracy characteristics of nanoparticle measuring instruments.

The standard deviation of the random error component $S_{L}, \%$, is calculated by the formula:

$S_{L}=\frac{\sqrt{\frac{\sum\left(L_{i}=\bar{L}\right)^{2}}{n(n-1)}}}{\bar{L}} \cdot 100 \%$,

where $L_{i}$ is the result of the $i$-th observation, nm; $\bar{L}$ is arithmetic mean of observation results, $\mathrm{nm}$; $n$ is the number of observations.

The number of observations at each investigated point of the measurement range $n$ is determined by the formula:

$$
n=\frac{2}{1-p} \text {, }
$$

where $p$ is the confidence level (at $p=0.95, n=40$ ).

Since the random component of the error is taken into account, and there is no variation, the number of observations calculated by formula (7) can be reduced to $n=10$.

Example of protocol of measurement results obtained in the Aerosol Instrument Manager software is shown in Figure 3.

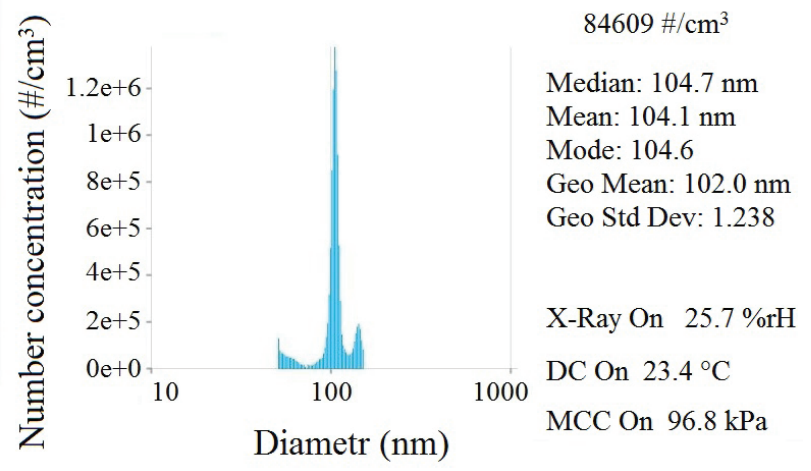

Figure 3 - Example of protocol for the measurement re-sults of nanoparticles with a nominal diameter of $100 \mathrm{~nm}$
The protocol displays the particle size distribution function in the range from 50 to $150 \mathrm{~nm}$. The median, mode, arithmetic mean, geometric mean and standard deviation of the geometric mean of the distribution function were also calculated.

We take the geometric mean value for the observation result.

The standard deviation of the random component of the error $S_{L}$ is $0.33 \%$.

\section{Determination of the error in transferring the size of a unit of length when measuring the size of nanoparticles in air}

The error in transferring the size of a unit of $S_{\Sigma}=\sqrt{S_{L}^{2}+\theta_{L}^{2}}$.

length when measuring the size of nanoparticles in air $\mathrm{S}_{\Sigma}, \mathrm{nm}$, is determined by the formula:

It is $2.42 \%$ with a confidence level of $P=0.95$; $K=1.1$.

\section{Conclusion}

The error in transferring the size of a unit of length when measuring the size of nanoparticles in air was $2.42 \%$ with a confidence level of $P=0.95$; $K=1.1$. This value of the error makes it possible to calibrate the counters of aerosol particles without resorting to purchasing standard samples of monodisperse latexes. Moreover, based on the results obtained, certification of standard samples of particle size in aerosols will be carried out. Also, the fact that the value of the error in transferring the size of a unit of length when measuring the diameter of nanoparticles was established by this method, and not using a comparison standard, allows us to assert that the analyzer of differential mobility of particles not only stores and transmits a unit of size, but also reproduces it.

\section{References}

1. Lux Research. Sizing Nanotechnology's Value Chain, 2004.

2. Gleiter H. Nanostructured materials: basicconsepts and microstructure. Actamater, 2000, vol. 48, pp. 1-29.

DOI: $10.1016 / \mathrm{S} 1359-6454(99) 00285-2$

3. Alymov M.I. Mechanical properties of nanocrystalline materials. Moscow: MIFI Publ., 2004, 32 p. DOI: $10.17277 /$ amt.2017.02pp.010-018 
4. Glezer A.M. Amorphous and nanocrystalline structures: similarities, differences, mutual transitions. Russian Chemical Journal, 2002, vol. XVLI, no. 5, pp. 57-63. DOI: 10.1134/S1087659612010038

5. Poole Ch., Owens F. Nanotechnology. Publishing house $5^{\text {th }}$. Moscow: Tekhnosfera Publ., 2010, 336 p.

6. NNI (National Nanotechnology Initiative) 2011, Environmental, Health, and Safety Strategy.

7. Tigges L., Wiedensohler A., Weinhold K., Gandhi J., Schmid H.-J. Bipolar charge distribution of a soft X-ray diffusion charger. J. Aerosol Sci., 2015, vol. 90, pp. $77-86$.

DOI: $10.1016 /$ J.JAEROSCI.2015.07.002

8. Kim J.H., Mulholland G.W., Kukuck S.R., Pui D.Y.H. Slip Correction Measurements of Certified PSL Nanoparticles Using a Nanometer Differential Mobility Analyzer (Nano-DMA) for Knudsen Number From 0.5 to 83. J. Res. Natl. Inst. Stand. Technol., 2005, vol. 110, pp. 31-54. DOI: 10.6028/jres. 110.005

9. ISO 15900:2020 Determination of particle size distribution - Differential electrical mobility analysis for aerosol particles. 